\title{
DNA Of A Successful BPO
}

Ravi S. Behara, Florida Atlantic University, USA

Somnath Bhattacharya, Florida Atlantic University, USA

\begin{abstract}
This paper identifies some of the critical elements of a successful BPO through a case study of an U.S. financial services firm that had BPO operations in India. The important dimensions of selection, training, motivation, respecting cultural differences, treating quality as paramount in all operations, and understanding how appropriate control has to be exercised in the area of knowledge-intensive services, were identified as being critical to success. Specific propositions are developed based on these critical elements, and provide a potentially new direction to service outsourcing research.
\end{abstract}

\section{INTRODUCTION}

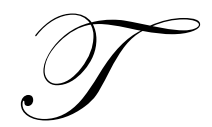

he service industry in western developed nations underwent significant growth in the 1970s and 1980s as work done within the home moved into the marketplace. This was followed by service work moving from within the confines of firms to the wider marketplace during the 1980s and 1990s. Now we are witnessing a significant restructuring and growth in the service sector because work that was traditionally done within organizations and nations has begun to enter the wider global marketplace.

Global outsourcing has entered its third phase in recent business history. Outsourcing of goods production was followed in the last couple of decades by an outsourcing of software development. But the emerging round of outsourcing is no sweatshop work! Boeing uses aeronautics specialists in Russia, Texas Instruments design chips in India, architects are being sourced in Hungary, U.S. brokerages, investment banks, and rating agencies are buying research and industry reports from finance specialists in India, accountants from the Philippines and Ireland are working on taxes and financial reports for U.S companies, and Indian IT professionals are remotely managing sophisticated networks for big Western corporations. Professional knowledge-intensive service work is now being outsourced around the world, and this is not simply a search for lowering operating costs. Companies are now sourcing the world for expertise in services. Yet about 50 percent of outsourcing deals fail to deliver the expected value (Craig and Willmott, 2005). Johnson (2006) reports that four out of five business process outsourcing contracts will need to be renegotiated within two years, and 20percent of all such contracts will collapse.

Firms place great emphasis on getting low prices to exploit the cost advantage that they essentially loose on performance guarantees and flexibility. The implementation and follow-through of outsourcing business deals are areas that have generally been the stages in which such companies have faltered. So this study investigates a successful BPO effort to attempt to uncover some of the key characteristics of success in offshore outsourcing.

The study will focus on the U.S.-India outsourcing context since India is the largest outsourcing partner to the U.S. in this endeavor. A case study of a financial services firm based in the US that outsourced some of its business process to a location in India is the basis of this paper. The detailed nature of the business as well as the actual locations in the US and India, together with the name of the organization, are not identified for confidentiality reasons. The firm will be referred to as Ace Financial Services or AFS in the remainder of the paper. The specific locations will be referred to as AFS (US) and AFS (India). The approaches used to effectively manage the outsourced business process are investigated, and specific propositions are developed based on these critical elements of success. 


\section{LITERATURE REVIEW}

Outsourcing has been viewed as a form of external provision of goods and/or services by another enterprise that would previously have been offered in-house. Outsourcing practice can be traced back to eighteenth-century England and has been in continuous use in numerous industry sectors but has received renewed attention in the latter half of the 1980s and 1990s in the emerging service sector. An initial research focus on services outsourcing dates back about a decade to the mid 1990s (McLaughlin and Fitzsimmons, 1996). The evolving literature on outsourcing has been concerned with "make-or-buy", or "in source-out source" decisions in relation to the behavior of enterprises and transaction cost economics. However, economic analysis has its limitations as it does not account for the leadership and management capabilities to structure and manage co-operative relationships crucial to the effective working of outsourcing arrangements.

In keeping with the twin themes of economic analysis and the leadership requirements for the effective running of outsourcing arrangements, it is considered that a paradigm shift has taken place that is termed the Westernization of the kieretsu model. Increasingly, service providers are becoming part of the client's overall business plan so that both the business and the outsourcing company can move forward together and build a longterm relationship of a modified keiretsu type. Such developments, in turn, create new organizational forms, based on an extended enterprise model, creating an organization that aims to gain a competitive edge by integrating internal information systems and business processes with those of customers, business partners and suppliers (Kakabadse and Kakabadse, 2000).

The emergence of such relationships in the outsourcing context brings the issue of managing business risk to the fore (Schniederjans and Zuckweiler, 2004). Considering that trust provides the glue of the Japanese kieretsu conglomerate, and that twenty-first century kieretsu-type relationships will need to be managed by understanding business risk to all partners involved in the relationship.

However, much of the past research in outsourcing has focused primarily on economics, quality, and to a certain extent on innovation. The following areas have been identified as needing better understanding: knowledge transfer, customer satisfaction, and business risk. More specifically, managing business risk in the outsourcing relationship in knowledge-intensive services involves issues such as: understanding shared risk, provide seamless service, business process management, complex co-ordination task, capacity to tap into a service provider's enabling expertise, technology and resources, managing portfolio of relationships, employee management, flexibility based on rapid and full sharing of information, control through co-operation, monitoring and sharing of benefits and risks, emphasis on risk and project management, effective partnership negotiation and conflict resolution (Salonen, 2004). While these issues are relevant to all knowledge-intensive professional services, specific variances of these issues when considering an international context also need to be investigated.

Others have taken a more analytic approach by developing business decision models to help facilitate a firm to formulate a business process outsourcing strategy. Kumar et al. (2007) present a toolkit for deciding what and when to outsource in order to optimize a company's process metric, profitability or productivity while minimizing risks and exposures. In their case study, India is identified as the destination of choice that generates the highest cash flow per year, when compared with alternative destinations of the U.S. and South Africa. Pai and Basu (2007) take a different approach by address managerial and legal issues related to technology outsourcing. While they pay close attention to intellectual property rights are related issues, there is a larger set of issues that are also applicable to BPO efforts. They identify the importance of compliance issues, contractual obligations, and due diligence to service agreements can affect the success of an outsourcing relationship.

From a managerial perspective, research on offshore outsourcing has identified some broad concerns including infrastructure, cultural differences, accents, language ability, contractual problems, and fear of reduced service levels (Tapper, 2004; Walsham, 2001). More specifically Mehta et al. (2006) investigated the challenges and opportunities of BPO firms in India. They found that firms need to rethink their business goals, revamp their organizational structures, and improve client-vendor relations, at the strategic level. At the operational level, firms needed to address human resources challenges such as employee motivation, attrition, and training and development. 
In a study that focuses on the problem of employee retention in Indian BPO firms, Bhatnagar (2007) found that a good level of employee engagement may lead to high retention, but this impact lasts for a limited time, and suggests more rigorous employee engagement that addresses employees' passion for learning, provide them with challenging opportunities that make them co-wealth creators, and to develop a deeper psychological contract with them through quality mentoring.

This study also attempts to understand success in Indian BPO firms by studying a generally successful US Financial Services' BPO operation in India. But the focus in on the internal structural characteristics that make a BPO successful. An analysis identifies interesting dimensions of outsourced service operations that need to be addressed by managers. These are presented in the form of propositions in this paper.

\section{OFFSHORING SERVICES TO INDIA}

The reemergence of the Indian and Chinese economies as major players in the global economy invokes memories of the early $19^{\text {th }}$ century when both these economies were dominant forces in the world. When we take a historical perspective, we can see that this is not the first time that China and India have had a large influence on the world economy. In 1820, China was the leading economy and accounted for about 29 percent of global GDP and India for about 16 percent. So these two economies together represented about 45 percent of global GDP in the early $19^{\text {th }}$ century. With such a strong legacy and a human capital that has since settled around the world and developed great expertise, it is no surprise that today China is a manufacturing giant and India is dominant in software and information technologies. It is in this context that the dominance of India in global IT-enables services, such as BPO, has to be understood. The fact that India is the leading destination for offshored outsourcing in IT services and BPO activities is well established. The choice of India as a location for BPO is not simply one of economics. The quality, speed, process orientation of work done in India has become as much a factor in its dominance.

Business Process Outsourcing continues to grow rapidly in size and scope. This is especially true of offshored outsourcing. Beyond human resource and information technology management, the Indian BPO sector has begun to concentrate and specialize in niche areas such as finance, research and development, and health sciences. These areas offer tremendous potential for growth and profitability. Finance and accounting area processes include internal auditing, payroll, cash management, accounts payable/receivable, credits, fixed assets, contract management, and collections, tax and regulatory compliance, budgeting and SEC reporting. While the more routine operational processes are gradually getting outsourced, outsourcing is still limited in compliance work. But some firms have set up their own BPO operations in India to overcome compliance related challenges (Marshall and Heffes, 2007).

While outsourcing typically involves third-party providers, there is a distinct offshoring trend in the development of wholly-owned subsidiaries. According to the research firm Gartner, the size of the global BPO market by 2007 is estimated to be $\$ 173 \mathrm{bn}$, of which $\$ 24.23 \mathrm{bn}$ would be outsourced to offshore providers. India has the potential to generate $\$ 13.8 \mathrm{bn}$ in revenue, a significant proportion of the total value. The projection includes revenues of Indian BPO service providers, captives operations of global players operating in India, and other third party service providers. For India, North America constitutes about 60 percent of the BPO market, Western Europe about 22 percent, the Asia Pacific region another 18 percent (BPO India, 2007).

Specifically, India is now the most preferred financial services outsourcing destination that can offer highend and mission critical support services. Functions being offshored have graduated from the support functions such as financial and accounting support and voice based services to complex research and analytic functions including financial modeling, equity research support and portfolio tracking. Firms are realizing cost savings in the range of thirty to fifty percent. In addition to cost savings, other crucial factors driving offshoring to India include regulatory compliance requirements, large-scale availability of skilled personnel, English speaking capabilities and favorable cultural issues. Over half the world's largest banks have offshored to India. Global financial service providers with captive service centers in India include HSBC, AXA, Citigroup, Deutsche Bank, ABN Amro, Goldman Sachs, Lehman Brothers and UBS. Large Indian BPOs such as Genpact, IBM Daksh, ICICI Onesource, WNS and Wipro 
BPO also provide services to global financial service firms. Smaller Indian providers including Amba Research, Irevna and Copal Partners that have captured the high-end research and analytics work. (BPO Times, 2007). But the sub-prime mortgage crisis in the U.S. and the weakening of the US Dollar have rendered several rude shocks to the outsourcing industry in 2007 and 2008. But these concerns are being somewhat offset by emerging outsourcing in the domestic Indian market, and new opportunities of maturing regions such as Europe, Middle East, and Asia (BPO India, 2008).

\section{CASE: ACE FINANCIAL SERVICES (INDIA)}

This paper discusses Ace Financial Services' (a U.S. company-owned financial services company) India unit. The unit is referred to as Ace Financial Services (India) or AFS (India) for short in the following discussion. It is a company-owned offshore unit providing internal services, but whose success has led to the company expanding the unit's role to also becoming a third-party service provider. Following an extensive review of the literature, some of which is presented in the previous sections, interviews were conducted with the senior U.S. executive responsible for outsourcing. These were initial exploratory interview followed by a semi-structured interview to gain a better understanding of the rationale and strategy behind the outsourcing, and the way it was implemented. Permission was also obtained from the senior executives at the company to visit and interview executives and managers at the AFS (India) unit of the company. One of the researchers visited the Indian unit for three days (and nights, since some managers worked the night shift). A total of about 30 hours of interviews were conducted. The same protocol of the semi-structured interview was used with all managers. The General Manager (Chief Executive in India) was interviewed at the very start and at the end of the visit. All interviews were recorded. Confidentiality of each interview, from local and U.S. superiors, was assured. Finally, an interview was conducted with the US executive for outsourcing. Both interviews with the executive in India and the U.S. that were conducted at the end of the interviewing process was specifically useful in establishing the validity of much of the issues identified in the following discussion. Some of the specifics have been removed in the following discussion to maintain the confidentiality of the identity of the firm and the employees. However, that does not detract from the discussion in any substantial way.

\section{DISCUSSION}

The following performance shaping factors were identified, through an extensive interview process, as being critical to the success of an offshored BPO. It is well recognized that a robust technology platform is a necessary, though not sufficient, condition for success of an IT-enabled outsourcing effort. Hence the following discussion does not explicitly focus on that issue.

\section{DNA \#1: Matching Employee Profiles}

AFS (India) takes a proactive effort at matching the nature of tasks to employee skills that are identified through a battery of standardized tests. Such efforts are not necessarily unique in the Indian outsourcing context, but AFS (India)'s efforts appear to go beyond those of other firms and encompass testing both behavioral and cognitive characteristics of applicants. Managers' competencies are also matched not just to the technical content but also to the nature of the processes they manage. The latter is especially significant in a BPO environment.

Proposition 1: A structured approach to evaluating and matching employee and manager behavioral and cognitive competencies to the process and tasks at hand, is essential for achieving successful offshored BPO operations.

\section{DNA \#2: Training For A "New" Context}

The uniqueness of training at AFS (India) is the fact that new employees do not have an understanding of the specific type of financial services since the Indian financial industry is in its infancy in this specific domain. While this has the advantages of starting without prejudice and with "clean slate" regarding this specific domain of financial industry knowledge, it also becomes a challenge to educate employees on the nuances of the business. The variety of approaches used, including extensive case studies, is central to delivering effective training. Classroom 
training continues to be very effective in helping employees assimilate academic information. This is followed by "hands-on" training. Coaches then help employees translate this new knowledge into consistently good practice on the production floor. Employee "hand-holding" by experienced coaches, and ongoing support over prolonged periods of time, are the prerequisites for high quality performance in a knowledge-intensive environment. The extent of initial training and ongoing training has been among the primary drivers of service quality.

Proposition 2: Extensive traditional and on-the-job training are essential for a successful offshored BPO effort in knowledge-intensive services.

\section{DNA \#3: Return Of Employees}

Employees form the core of operational excellence in any service. But they are even more critical in knowledge-intensive services. However, employee retention is considered amongst the biggest challenges facing managers in services outsourcing environment in India. Employees are usually attracted by new firms entering the market that offer higher compensation, impressive job titles, and/or have a more recognizable name (brand recognition). The BPO environment is no exception, and the labor environment is extremely competitive. The employee loyalty issue is further heightened by the fact that many employees are young, either having just graduated or still enrolled in universities. The presence and arrival of companies with global marquee names makes retention a special challenge, especially in the major cities. In addition, AFS (India) faces the twin challenges of not being a name that is easily recognized in an industry (their specific domain within financial services) that is nascent in India. So the only way to attract and retain the best talent has been to create a work environment that results in the highest levels of employee satisfaction. AFS (India) has achieved this through various means such as good training, facilities, employee services, maintaining a professional culture, job enrichment, and an overall effective management of the unit. It is to AFS (India)'s credit that there are many instances in which employees leaving the company for "greener pastures" have returned or requested to rejoin the company.

Proposition 3: Maintaining a high level of employee satisfaction through a well managed work environment that results in high numbers of returning employees is an essential for a successful offshore BPO initiative.

\section{DNA \#4: Pseudo-Immigrant Motivation}

While the employees at AFS (India) are physically located in India, their intellectual and emotional locus are in the US where their customers and process-partners (within and outside Ace Financial Services) are all located. This working context sets the stage for a "pseudo-immigrant" context in which there is a need for such employees to demonstrate excellence in performance across many dimensions. There is also a strong sense for the need to continually learn about the "new" environment in order to survive and succeed. Success in these efforts is not an option but a necessity for survival. Such a mindset is an excellent driver for the necessary motivation to deliver sustainable levels of high quality.

Proposition 4: A "pseudo-immigrant" motivation drives employees to succeed by continually learning in an offshore BPO environment.

\section{DNA \#5: Mutual Trust/Respect From Greater Cultural Awareness}

Much of the offshoring activities in India are in IT and IT-enabled services. These essentially involve knowledge workers. Much of the earlier work in both areas has been at the "lower end" of the value chain such as coding or call-center services. This has necessarily been the starting position of most organizations as they become more aware of Indian firms and Indians as a business partners. It is also obviously a matter of managing operational and business risk in a new and (usually) unfamiliar environment. But the consequence of such a beginning is that many "home office" employees (US) develop a tendency to view the offshored facility as "inferior," albeit knowledge-intensive. So even when more "advanced" service processes at the "higher end" of the value chain are executed at AFS (India), there is a tendency by some Ace Financial Services (US) employees to exhibit controlling behaviors that are consistent with managing an "inferior" group. Such behavior is especially detrimental in a 
knowledge-intensive service environment. However, the heart of the matter in such issues is the issue of trust. A broad awareness of the history and culture of India would certainly facilitate Ace Financial Services (US) employees achieving a "trust-threshold" and maintaining a healthy respect for individuals on either side of the global effort. Striking this balance is critical in a knowledge-intensive work environment as employee capabilities are brought to bear on the task most effectively in an atmosphere of mutual respect and empathy. AFS (India) employees would also benefit from an exposure to US history and culture, that go beyond the typically (US) accent training. Employees on both continents appear to be constrained by misconceptions of the "other side" that are usually shaped by the popular media and have very little to do with the actual people they interact with during the service delivery process. This is a significant roadblock to the effective management of distributed intelligence (elements of which are separated by large distances) which is central to a BPO effort.

Proposition 5: A deeper knowledge of the offshore BPO country's history and culture is essential for corporate employees to cross a "trust and respect threshold" beyond common language (English), thereby enhancing the possibilities of a successful BPO effort.

\section{DNA \#6: Quality Before Production}

While it has always been academically suggested that quality precede volume production, it has typically not been the case in most organizations, especially when under delivery pressures. This has been a consistent management failure across many industries. As such it is certainly a breath of fresh air (if not thinking) to find that AFS (India) has diligently enforced the priority of quality before volume production in all their processes. Managers have also educated employees on two distinct (but related) issues related to quality of work. While customer satisfaction through high quality is important, it is also important for employees to recognize the fact that their very jobs (offshored) would not be viable if they performed poorly. Hence the need for quality is seen as a necessary condition for survival. A job's location in a globally competitive economy is not bound by national borders but by skills and competencies made explicit through consistently delivering high quality. Hence lower quality, even with increasing production volumes, is not an option. Further, managers take advantage of a greenfield quality culture by promoting only employees who consistently do high quality work. An unintended, but welcome, side-effect of high quality at AFS (India) has been that it has raised the bar for performance in Ace Financial Services' US domestic units. Indian managers' participation in US-based six sigma teams completes the feedback loop for joint quality improvement efforts where new ideas are explored and new projects initiated.

Proposition 6: Establishing quality before increasing production volumes across all service processes is essential to offshore BPO success.

\section{DNA \#7: Partnership With Corporate}

Corporate support always exists for the various units of an organization. That explains their very existence. However, the extent and nature of support varies. Typically such relations are a "one-way street" driven by the power that resides at corporate. This is usually seen in areas such as performance evaluation. However, a two-way (if not a 360 degree) evaluation process would bring the relationship to a better balance. This again is a sign of a maturity in the relationship and is essential for knowledge-intensive service work. It is simply not possible to provide an effective service if the inputs of information and knowledge from Ace Financial Services (US) and AFS (India) are not accurate, timely or reliable. In this case, Ace Financial Services (US) is not merely "corporate" but also a part of the business process where every succeeding step in the process is the customer of the prior step. This realization involves a significant amount of training for US-based employees involved in the business processes conducted at AFS (India). Further, the boundaries of the roles of such employees have to be defined and maintained. It must be recognized that being from Ace Financial Services (US) is neither a necessary nor sufficient reason to get involved in processes or activities that are beyond the scope and responsibility of any individual employee. Also, another sigh of the maturity of the relationship is when the BPO is viewed more than being merely a set of process performed at a remote location, but being an operating unit of the organization. Such a realization would be accompanied with greater independence (and non-interference) in decision making on operational matters and personnel decisions (such as promotion and compensation), at the unit-level. 
Proposition 7: A mature corporate office - offshored BPO unit relationship is essential to offshore BPO success. This is characterized by greater independence for the unit in operational and personnel matters; but a greater codependence in process matters.

\section{DNA \#8: Process Appropriate Control}

Organizational controls on AFS (India) that are exerted from Ace Financial Services (US) are an essential element of the organizational infrastructure. Further, the nature of controls is also consistent with the level of trust that exists between the two entities. However, the extent and type of control that exists should not be universal but contingent on the nature of the process. This is especially significant in the context of regulatory compliance issues such as the Sarbanes-Oxley Act. Self-monitored and regulated processes are the logical conclusion in the case of knowledge work. The realization of such an approach would be a sign of maturity in any BPO organization.

Proposition 8: A mature corporate office - offshored BPO unit relationship is essential to offshore BPO success. It is characterized by a process-appropriate level of control that is exercised from either corporate or the offshore unit.

The important dimensions of personnel management, understanding and respecting cultural issues, treating quality as paramount in all operations, and understanding how control has to be exercised in the area of knowledgeintensive services, have been gleaned through an extensive case study of the financial services firm in this study.

\section{CONCLUSIONS}

The strength and success of a BPO effort in this case showed that the twin issues of business performance and mutual respect are not mutually exclusive in knowledge-intensive services. While the various dimensions of business performance are being addressed, there is a significant need for employees on both sides of the effort (US and India) to learn and respect the other culture, while maintaining a healthy respect for their own. A typical (clichéd) example would be for US employees to misinterpret the apparent politeness or diffidence of their Indian counter part as being "weak," while Indian employees misinterpret apparent politeness or encouragement as being a sign of "affirmation." The commonality of language (English) should not be mistaken for a commonality of worldviews. An effective way to address this is through the recruitment of managers with foreign experience, both in the US and in India.

BPO is essentially an effort to leverage (and migrate) the intellectual capital of other locations without the physical migration of peoples. When people migrate, they tend to reorient and balance their cultures with those of the host nation. However, in BPOs, there is no physical migration. Hence there is a constant need to understand and manage intellectual capital remotely though an understanding and respecting the individual cultures through the use of appropriate levels of control.

The propositions developed in this study provide an interesting and important point of departure for research in services outsourcing. Much of the past work has focused on the reasons to outsource, how it relates to a firm's strategy, or simply how to select the appropriate location, service provider, and mitigate risk from a business or process perspective. Since outsourcing is here to stay in services, it is time to gain a better understanding of how to make it work effectively. This study provides some additional dimensions in this regard.

\section{REFERENCES}

1. Bhatnagar, Jyotsna (2007). Talent management strategy of employee engagement in Indian ITES employees: key to retention, Employee Relations, Vol. 29 No. 6, pp. 640-663.

2. BPO India (2007). Global Market Size of BPO http://bpoindia.blog.com/1510346/ accessed on 20 June 2008.

3. BPO Times (2007). India Tops As Financial Services Outsourcing Destination, http://www.bpotimes.com/efytimes/fullnewsbpo.asp?edid=16513\&magid=25 accessed on 23 June 2008. 
4. BPO India (2008). BPO 2008: The Year Ahead http://www.bpoindia.org/research/bpo-2008-yearahead.shtml accessed on 20 June 2008.

5. Craig, D. and P.Willmott (2005). Outsourcing grows up, The McKinsey Quarterly, Web exclusive, Feb 2005, http://www.mckinseyquarterly.com accessed on 1 April 2008.

6. Johnson, Lauren Keller (2006). Successful Business Process Outsourcing, Sloan Management Review, V47, no 2. pp. 5-6.

7. Kumar, Sameer; Aquino, Edgardo C.; Anderson, Elizabeth (2007). Application of a process methodology and a strategic decision model for business process outsourcing, Information Knowledge Systems Management, Vol. 6 Issue 4, p323-342.

8. McLaughlin, C.P. and J.A. Fitzsimmons (1996). Strategies for globalizing service operations, International Journal of Services Industries Management, Vol. 7, No. 4, pp. 43-57.

9. Mehta, Anju; Armenakis, Achilles; Mehta, Nikhil and Irani, Feruzan (2006). Challenges and Opportunities of Business Process Outsourcing in India, Journal of Labor Research, Vol. 27 Issue 3, p324-338.

10. Marshall, Jeffrey and Heffes. Ellen M. (2007). BPO: Developing Market, Evolving Strategies, Financial Executive. Vol. 23, No. 5; p. 38-44.

11. Kakabadse, N. and Kakabadse, A. (2000). Outsourcing: a paradigm shift, Journal of Management Development, Vol. 19, No. 8, pp. 670-728.

12. Pai, Arjun K. and Basu, Subhajit (2007), Offshore technology outsourcing: overview of management and legal issues, Business Process Management Journal 13, no. 1, pp. 21-46.

13. Salonen, A. (2004). Managing outsourced support services: observations from case study Facilities, Vol. 22, No. 11/12, pp. 317-322.

14. Schniederjans, M.J. and K.M. Zuckweiler (2004). A quantitative approach to the outsourcing-insourcing decision in an international context, Management Decision, Vol. 42, No. 8, pp. 974-986.

15. Tapper, David (2004). Worldwide and U.S. IT Outsourcing Services 2004-2008 Forecast: A Potential Perfect Storm, Market Analysis (April 2004): IDC, Document 31089, www.idc.com.

16. Walsham, Geoff (2001). Making a World of a Difference. Chichester: Wiley. 